\title{
RHEOLOGICAL ANALYSIS OF VEGETABLE OILS USED FOR BIODIESEL PRODUCTION IN BRAZIL
}

\begin{abstract}
L. E. Silva a , ABSTRACT
C. A. C. Santos ${ }^{a}$,

J. E. S. Ribeirob,

C. C. Souza ${ }^{b}$,

and A. M. S. Sant'Anab

${ }^{a}$ Universidade Federal da Paraíba

Centro de Tecnologia

Programa de Pós Graduação em Engenharia

Mecânica

Bairro: Cidade Universitária

CEP 58.051-900, João Pessoa, Paraíba, Brasil eloicefet@gmail.com

carloscabralsantos@yahoo.com.br

${ }^{\mathrm{b}}$ Universidade Federal da Paraíba Centro de Tecnologia

Programa de Pós Graduação em Ciência e

Tecnologia de Alimentos

Rheology attempts to define a relationship between the stress acting on a given material and the resulting deformation and/or flow that takes place. Thus, the knowledge of rheological properties of fluid materials such as vegetable oils generates auxiliary data that can be used in its storage and application. In this context, the aim of this study was to evaluate the rheological behavior of vegetable oils (cotton, canola, sunflower, corn and soybean) at different temperatures, using four rheological models (Ostwaldde-Waelle, Herschel-Bulkley, Newton and Bingham). The rheological properties were determined using a Thermo Haake rheometer with concentric cylinder geometry. Measurements were taken at 30,45 and 60 ${ }^{\circ} \mathrm{C}$ by controlling the temperature using a thermostatic bath coupled to the equipment. The software Rheowin Pro Job Manager was used for process control and data record. The rheograms were obtained by measuring the values of shear stress varying the shear rate from 100 to $600 \mathrm{~s}^{-1}$ within 250 seconds. For the analysis of the apparent viscosity at different shear rates was applied simple linear regression until 2nd degree with the aid of SAS (SAS/Stat 9.2) program. The apparent viscosity data were submitted to analysis of variance and the averages were compared by Tukey test at $5 \%$ of probability. Higher temperatures of the samples were correlated to lower shear stress values, hence lower values for viscosity and consistency index were obtained, since it is known that the density and viscosity are highly sensitive to temperature and that the increase in temperature results in reduction of viscosity, benefiting the fluid flow. The models of Newton and Ostwald-de-Waelle were chosen to evaluate the rheological behavior of the samples, showing a good fit for the rheological data.
\end{abstract}

Bairro: Cidade Universitária

CP. 58.051-900, João Pessoa, Paraíba, Brasil

Received: September 08, 2015

Revised: October 08, 2015

Accepted: November 09, 2015
Keywords: temperature, rheological modeling, vegetable oils

\section{NOMENCLATURE}

K Consistency index, Pa $\mathrm{s}^{\mathrm{n}}$

$\mathrm{n} \quad$ Flow behavior index, (dimensionless)

\section{Greek symbols}

$\gamma \quad$ Shear rate, $\mathrm{s}^{-1}$

$\eta \quad$ Bingham plastic viscosity, Pa's

$\mu \quad$ Viscosity, Pa's

$\tau \quad$ Shear stress, $\mathrm{Pa}$

\section{Subscripts}

$0 \quad$ Yield point

\section{INTRODUCTION}

The use of oil plants in the industry is one of the most important activities of Brazil's agribusiness, since vegetable oils is used in food, cosmetic, pharmaceutical and chemical industries. Currently they are in the biofuels industry to a huge market for biodiesel production (Carlsson, 2009; Azam et al., 2005). There are several reasons why biodiesel is considered promising for developing and industrialized countries, such as: energy security, environmental concerns, foreign exchange savings, and socioeconomic issues related to the rural sector (Rajasekar and Selvi, 2014). The highlight of Brazil in the production of biodiesel is in its high biodiversity and productivity of grain that can be used to extract vegetable oils. This is due in part to its continental size, location in a tropical area, the existence of abundant water resources, besides immense unoccupied areas. Since the industrial revolution, the different forms of energy have become essential for humans to retain the standard of living and maintain economic growth. In a few decades, fossil fuels, especially petroleum, natural gas and coal played an important role in fulfilling this demand for energy. However, it has non-renewable character (Ashraful et al., 2014) and releases large amounts of greenhouse gases. When considering the 
process of consolidation that is currently happening with renewable energy, biodiesel is a suitable choice, offering alternatives for solving economic, social and environmental problems (Candeia et al., 2011; Rodrigues Filho, 2009).

The flow behavior and rheological properties of solutions, suspensions and mixtures have great influence on the manufacturing process and stability of these products. The evaluation and control of these properties are essential requirements for the selection of a material in certain industrial applications (Tabilo-Munizaga and Barbosa-Cánovas, 2005). It is known that biodiesel produced from vegetable oils carries part of the original matrix properties (Lôbo et al, 2009) and that larger molecular chains of the triglycerides contained in vegetable oils result in higher viscosity, higher density and lower volatility compared to diesel. This, in turn, causes poor fuel atomization (Selim, 2009). Thus, the knowledge of rheological properties in the manufacturing of products provides data that can be used in its storage and processing (Melo, 2010). In this context, the aim of this study was to evaluate the rheological behavior (at different temperatures) of several vegetable oils (cotton, canola, sunflower, corn and soybean) used for biodiesel production in Brazil.

\section{EXPERIMENTS}

\section{Materials}

All vegetable oils (cotton, canola, sunflower, and soybean) were purchased in the local market and used without further treatment.

\section{Rheological characterization}

The rheological properties were determined using a Thermo Haake (model VT550, Thermo Haake, Karlsruhe, Germany) with concentric cylinders geometry (MV/MV1). Measurements were taken at 30,45 and $60{ }^{\circ} \mathrm{C}$, and the temperature was controlled by a thermostatic bath coupled to the equipment (Thermo Haake, Karlsruhe, Germany). For process control and data recording was used the Rheowin Job Manager Pro software that controls system operations. The rheograms were obtained by measuring values of shear stress by varying the shear rate from 100 to $600 \mathrm{~s}^{-1}$ during 250 seconds. All measurements were performed in triplicate, using a new sample for each repetition, and the mean value of the replicates was used to calculate the rheological parameters. The modeling was performed by fitting the data to the models of Ostwald-de-Waelle, Herschel-Bulkley, Newton and Bingham. The software Statistica 7.0 (Statsoft, USA) was used for the calculation. For the analysis of the apparent viscosity at different shear rates a simple linear regression until 2nd degree was applied with the aid of SAS (SAS/Stat 9.2) program.

\section{Mathematical equations}

Equations below correspond to the fitting models.

$$
\begin{gathered}
\text { Newton: } \tau=\mu \cdot \gamma \\
\text { Bingham: } \tau=\tau_{0}+\eta \cdot \gamma \\
\text { Ostwald-De-Waelle: } \tau=K \cdot \gamma^{n} \\
\text { Herschel-Bulkley: } \tau=\tau_{0}+\mathrm{K} \cdot \gamma^{\mathrm{n}}
\end{gathered}
$$

where: $\tau$ is the shear stress (Pa); $\tau_{0}$ is the yield stress $(\mathrm{Pa}) ; \gamma$ is the shear rate $\left(\mathrm{s}^{-1}\right)$; $\mathrm{n}$ is the flow behavior index (dimensionless); $\mathrm{K}$ is the consistency index $\left(\mathrm{Pa} \cdot \mathrm{s}^{\mathrm{n}}\right) ; \mu$ is the viscosity $(\mathrm{Pa} \cdot \mathrm{s})$ e $\eta$ is the Bingham plastic viscosity $(\mathrm{Pa} \cdot \mathrm{s})$.

\section{RESULTS AND DISCUSSION}

All samples showed a linear behavior during flow "Fig. 1A, 1B, 1C, 1D and 1E "evidenced also by the values of flow behavior index near to 1 , shown in "Tab. 1". Small oscillations were observed for shear rate exceeding $400 \mathrm{~s}^{-1}$. The increase of the temperature of the samples was related to lower values for the shear stress, thus lower values of viscosity and consistency index were observed by increasing the temperature. It is well known that the density and viscosity are highly sensitive to temperature and increased temperature results in reduced viscosity, benefiting the fluid flow as also reported by Gao and $\mathrm{Li}$ (2012).
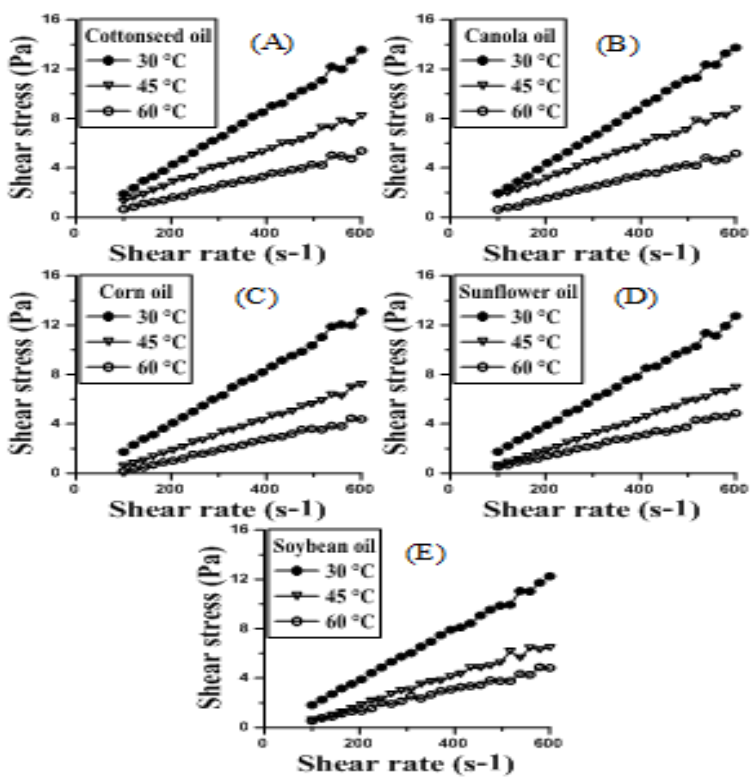

Figure 1. Shear stress as a function of shear rate for vegetable oils at different temperatures (30, 45 and $60{ }^{\circ} \mathrm{C}$ ). (A) is cottonseed oil, (B) is Canola oil, (C) is corn oil, (D) is sunflower oil and (E) is soybean oil. 
Table 1. Rheological parameters of the vegetable oils obtained by fitting the experimental data to the rheological models.

\begin{tabular}{|c|c|c|c|c|c|c|c|c|c|c|c|c|}
\hline \multicolumn{13}{|c|}{ Temperature: $30^{\circ} \mathrm{C}$} \\
\hline \multirow{4}{*}{ Oils } & \multicolumn{11}{|c|}{ Models } & \\
\hline & \multicolumn{2}{|c|}{ Newton } & \multicolumn{3}{|c|}{ Bingham } & \multicolumn{3}{|c|}{ Ostwald-de-Waelle } & \multicolumn{4}{|c|}{ Herschel-Bulkley } \\
\hline & \multicolumn{2}{|c|}{$\tau=\mu(\gamma)$} & \multicolumn{3}{|c|}{$\tau=\tau_{0}+\eta(\gamma)$} & \multicolumn{3}{|c|}{$\tau=\mathbf{K}(\gamma)^{\mathbf{n}}$} & \multicolumn{4}{|c|}{$\tau=\tau_{0}+\mathbf{K}(\gamma)^{\mathbf{n}}$} \\
\hline & $\mu$ & $\mathbf{R}^{2}$ & $\tau_{0}$ & $\eta$ & $\mathbf{R}^{2}$ & $\mathbf{K}$ & n & $\mathbf{R}^{2}$ & $\tau_{0}$ & $\mathbf{K}$ & n & $\mathbf{R}^{2}$ \\
\hline Cotton & 0.0217 & 0.996 & -0.3334 & 0.0225 & 0.998 & 0.0160 & 1.0507 & 0.998 & -0.1902 & 0.0194 & 1.0222 & 0.998 \\
\hline Canola & 0.0223 & 0.997 & -0.4309 & 0.0234 & 0.999 & 0.0151 & 1.0644 & 0.999 & -0.2099 & 0.0186 & 1.0333 & 0.999 \\
\hline Sunflower & 0.0202 & 0.995 & -0.4011 & 0.0212 & 0.998 & 0.0134 & 1.0678 & 0.998 & -0.4297 & 0.0218 & 0.9954 & 0.997 \\
\hline Corn & 0.0211 & 0.995 & -0.4286 & 0.0221 & 0.999 & 0.0141 & 1.0665 & 0.998 & -0.3094 & 0.0195 & 1.0187 & 0.998 \\
\hline Soybean & 0.0199 & 0.997 & -0.1974 & 0.0204 & 0.998 & 0.0164 & 1.0323 & 0.998 & -0.1340 & 0.0190 & 1.0107 & 0.998 \\
\hline \multicolumn{13}{|c|}{ Temperature: $45^{\circ} \mathrm{C}$} \\
\hline \multirow{5}{*}{ Oils } & \multicolumn{12}{|c|}{ Models } \\
\hline & \multirow{2}{*}{\multicolumn{2}{|c|}{ Newton }} & \multirow{2}{*}{\multicolumn{3}{|c|}{ Bingham }} & \multirow{2}{*}{\multicolumn{3}{|c|}{ Ostwald-de-Waelle }} & \multirow{2}{*}{\multicolumn{4}{|c|}{ Herschel-Bulkley }} \\
\hline & & & & & & & & & & & & \\
\hline & \multicolumn{2}{|c|}{$\tau=\mu(\gamma)$} & \multicolumn{3}{|c|}{$\tau=\tau_{0}+\eta(\gamma)$} & \multicolumn{3}{|c|}{$\tau=\mathbf{K}(\gamma)^{\mathbf{n}}$} & \multicolumn{4}{|c|}{$\tau=\tau_{0}+\mathbf{K}(\gamma)^{\mathbf{n}}$} \\
\hline & $\boldsymbol{\mu}$ & $\mathbf{R}^{2}$ & $\tau_{0}$ & $\eta$ & $\mathbf{R}^{2}$ & $\mathbf{K}$ & n & $\mathbf{R}^{2}$ & $\tau_{0}$ & $\mathbf{K}$ & n & $\mathbf{R}^{2}$ \\
\hline Cotton & 0.0136 & 0.997 & -0.0061 & 0.0136 & 0.997 & 0.0137 & 0.9983 & 0.997 & -0.2542 & 0.0202 & 0.9414 & 0.997 \\
\hline Canola & 0.0147 & 0.993 & 0.3271 & 0.0139 & 0.997 & 0.0224 & 0.9306 & 0.997 & 0.3696 & 0.0129 & 1.0106 & 0.997 \\
\hline Sunflower & 0.0111 & 0.979 & -0.7017 & 0.0128 & 0.999 & 0.0032 & 1.2029 & 0.997 & -0.7194 & 0.0132 & 0.9953 & 0.999 \\
\hline Corn & 0.0111 & 0.973 & -0.7744 & 0.0212 & 0.998 & 0.0027 & 1.2305 & 0.996 & -0.6229 & 0.0098 & 1.0414 & 0.998 \\
\hline Soybean & 0.0106 & 0.972 & -0.6716 & 0.0122 & 0.992 & 0.0032 & 1.1953 & 0.989 & -0.9624 & 0.0204 & 0.9253 & 0.993 \\
\hline \multicolumn{13}{|c|}{ Temperature: $60^{\circ} \mathrm{C}$} \\
\hline \multirow{4}{*}{ Oils } & \multicolumn{12}{|c|}{ Models } \\
\hline & \multicolumn{2}{|c|}{ Newton } & \multicolumn{3}{|c|}{ Bingham } & Ost & Idd-de-Y & elle & & Hersche & ulkley & \\
\hline & $\tau=$ & & & $=\tau_{0}+\eta$ & & & $=\mathbf{K}(\gamma)^{\mathbf{n}}$ & & & $\tau=\tau_{0}$ & $K(\gamma)^{n}$ & \\
\hline & $\boldsymbol{\mu}$ & $\mathbf{R}^{2}$ & $\tau_{0}$ & $\eta$ & $\mathbf{R}^{2}$ & $\mathbf{K}$ & n & $\mathbf{R}^{2}$ & $\tau_{0}$ & $\mathbf{K}$ & n & $\mathbf{R}^{2}$ \\
\hline Cotton & 0.0085 & 0.987 & -0.2414 & 0.0091 & 0.992 & 0.0049 & 1.0919 & 0.992 & -0.2558 & 0.0094 & 0.9946 & 0.992 \\
\hline Canola & 0.0084 & 0.988 & -0.2581 & 0.0090 & 0.994 & 0.0050 & 1.0850 & 0.992 & -0.7153 & 0.0247 & 0.8529 & 0.995 \\
\hline Sunflower & 0.0078 & 0.983 & -0.3637 & 0.0086 & 0.995 & 0.0030 & 1.1568 & 0.995 & -0.4782 & 0.0116 & 0.9567 & 0.994 \\
\hline Corn & 0.0069 & 0.952 & -0.6676 & 0.0085 & 0.995 & 0.0011 & 1.3067 & 0.988 & -0.8417 & 0.0132 & 0.9347 & 0.995 \\
\hline Soybean & 0.0078 & 0.983 & -0.2734 & 0.0084 & 0.989 & 0.0039 & 1.1126 & 0.989 & -0.2978 & 0.0090 & 0.9902 & 0.989 \\
\hline
\end{tabular}

Table 2. Apparent viscosity of the vegetable oils at different temperatures (30,45 and $\left.60{ }^{\circ} \mathrm{C}\right)$.

APPARENT VISCOSITY (Pa·s)

Temperature $\left({ }^{\circ} \mathrm{C}\right)$

30

45

60

\begin{tabular}{ccccc}
\hline COTTON & CANOLA & SUNFLOWER & CORN & SOYBEAN \\
\hline $0.02123 \mathrm{abA}$ & $0.02177 \mathrm{aA}$ & $0.01983 \mathrm{dA}$ & $0.02055 \mathrm{bcA}$ & $0.01968 \mathrm{cdA}$ \\
$0.01301 \mathrm{bB}$ & $0.01507 \mathrm{aB}$ & $0.01025 \mathrm{cB}$ & $0.01020 \mathrm{cB}$ & $0.00971 \mathrm{cB}$ \\
$0.00820 \mathrm{aC}$ & $0.00800 \mathrm{aC}$ & $0.00738 \mathrm{aC}$ & $0.00616 \mathrm{bC}$ & $0.00726 \mathrm{aC}$
\end{tabular}

Means followed by the same lowercase and uppercase letters in rows in columns do not differ by Tukey test at $5 \%$ of probability.

Rheological studies usually involve relationships between shear rate and shear stress. When the relationship is linear, the fluid is Newtonian and said viscosity is constant regardless of the rate or applied stress. However, in many cases, this relationship is not linear and the fluid is classified as non-Newtonian. These may be pseudoplastic fluids, which exhibit a decrease in viscosity with increasing shear rate applied (Schramm, 2006). According to rheological analysis, it was possible to verify in all oils a Newtonian behavior, confirmed by the profile of the curves obtained, demonstrating an almost constant viscosity at different shear rates. The data obtained are in accordance with studies described in the literature
(Franco and Nguyen, 2011; Conceição et al., 2005; Santos et al., 2005).

As stated by Brock et al. (2008), whatever the form of obtaining or employment of vegetable oils, the knowledge of thermophysical properties is fundamental to the achievement of the stages of designing equipment and processes or even for product specification, especially in the biofuels industry where it is known that the viscosity of the biodiesel depends on the profile of the alkyl esters and thus the raw materials used for its production.

By a chemistry definition, Biodiesel is a mixture of alkyl esters of fatty acids, methyl or ethyl esters most often obtained by alcoholysis of triacylglycerols 
(TAG) present in vegetable oils or animal fats (Banković-Ilić et al., 2012). In the industrial economy of any country, diesel fuel plays an important role, especially in the transportation sector and its demand is increasing steadily. Moreover, the increased burning of petroleum-based fuels in internal combustion engines promotes impact on air quality, human health and global warming (Rizwanul Fattah et al., 2013). According Saad (2005) and Stavarache et al. (2005), the great compatibility of biodiesel with conventional diesel, characterizes it as an alternative able to meet most of the diesel vehicles already on the market, without any need for technology investments in the development of motor fleet. These data corroborate the final considerations of Rajasekar and Selvi (2014) who state that the mixture with pure biodiesel and biodiesel can be used as an environmentally friendly alternative fuel without any major change in internal combustion engines.

All the rheological models showed good fits to the experimental data, observing determination coefficients between 0.9520 and 0.9990 , explaining $95.20 \%$ to $99.90 \%$ of the variability of the experimental data as shown in "Tab. 1". However, despite the high determination coefficients observed for the models of Bingham and Herschel-Bulkley, negative values were obtained for the yield stress $\left(\tau_{0}\right)$ in these models, which has no physical meaning, showing that these models are inadequate to represent the rheological behavior of the samples tested, it was also evidenced by Kelessidis et al. (2005). Thus, the models of Newton and Ostwald-de-Waelle were observed to be the most appropriate models for the representation of the rheological behavior of the vegetable oils analyzed.

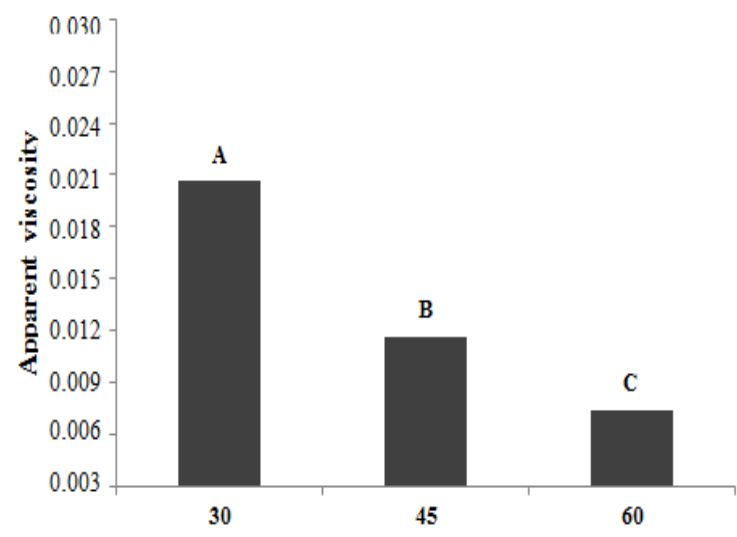

Figure 2. Overall average of the apparent viscosity of the oils at different temperatures (30, 45 and $60^{\circ} \mathrm{C}$ ).

* Different uppercase letters means a statistical difference by Tukey test at 5\% probability.

According to "Tab. 2" and "Figure 2", it was observed that temperature had a significant influence on the viscosity of the oils studied, which showed a decrease with the increase in temperature, ranging from 0.02177 (canola oil at $30{ }^{\circ} \mathrm{C}$ ) to 0.00616 (corn oil at $60^{\circ} \mathrm{C}$ ). At $30^{\circ} \mathrm{C}$, cottonseed oil was similar to canola and corn oils. At $45{ }^{\circ} \mathrm{C}$, the oils from cottonseed and canola were significantly different compared to the other and at $60{ }^{\circ} \mathrm{C}$ only the corn oil showed a significant difference. The cottonseed and canola oils presented significant differences for apparent viscosity in the range of $30-60{ }^{\circ} \mathrm{C}$, which did not occur for sunflower, corn and soybeans oils "Fig. 3".

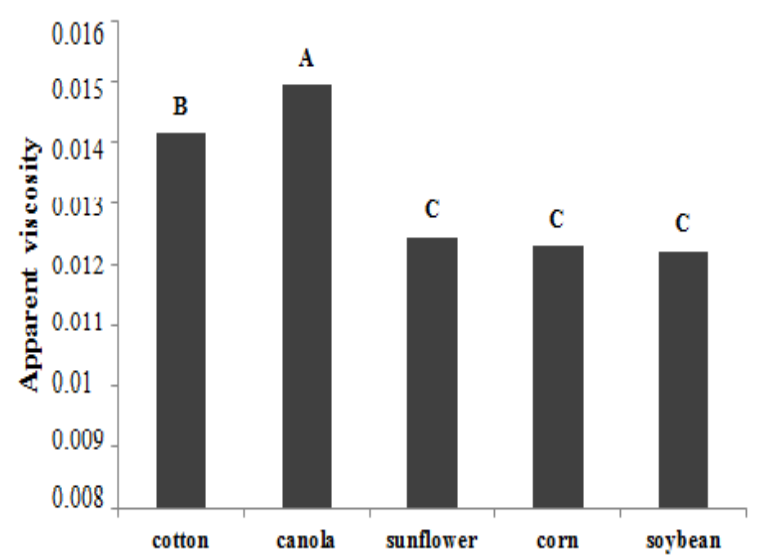

Figure 3. Apparent viscosity in the range of $30-60{ }^{\circ} \mathrm{C}$. *Means followed by the same uppercase letters do not differ by Tukey test at $5 \%$ probability.

Vegetable oils differ in their molecular structures, as well as their physical and chemical properties. Therefore, each resulting biodiesel may exhibit different characteristics (Hossain et al., 2010, Tan et al., 2012) also affected by the nature of the feedstock and efficiency of the conversion process used for their production (Lin and Hsiao, 2013). However, its combustion properties, such as viscosity, density, and other important properties must meet international standards. The law number 11.097 from January $13^{\text {th }}$, 2005, which discusses about the introduction of biodiesel in the Brazilian energy matrix defines biodiesel as "biofuel derived from renewable biomass for use in internal combustion engines with compression ignition or, in accordance with regulations, to another type power generation, which can partially or totally replace the fossil fuels". The ANP Resolution No. 14 of May 11, 2012 defines the specifications of the Brazilian biodiesel (www.anp.gov.br. Accessed on September 24, 2014).

The cost of raw materials is extremely high and represents over $70 \%$ of the total production cost of biodiesel (Kargbo, 2010). Biodiesel in Brazil uses mostly soybean oil and still has a high cost of production, with approximately $80 \%$ bound to the main raw material: vegetable oil (Pignelli, 2010). Thus, the characterization of the raw materials to be used in the production of biodiesel and search for alternative sources constitutes an important focus to make biodiesel more competitive with fossil fuels. In 
the current scenario of the Brazilian biodiesel production, notes the strong dependence of soybean oil (77.26\%) as raw material, noting that cottonseed oil also helps with this technology ("Fig. 4") being relevant fostering the participation of other sources of oil.

The viscosity is the resistance offered by a fluid and can be considered as integral interaction of the molecules forces (Esteban et al., 2012). There is a close relationship between the viscosity of vegetable oil and its temperature. In particular, the increase in temperature of the vegetable oils leads to reduction of its viscosity. High viscosity is one of the problems that present several consequences related mainly to fuel spray characteristics (Anand et al., 2009). Based on this principle, vegetable oils are preheated before being fed to the engines, thus reducing the problems discussed above (Yilmaz and Morton, 2011; Franco and Nguyen, 2011).

Although fuel spray penetration into the combustion chamber can be eventually promoted by higher viscosities of fuels, there are more adverse effects that can occur in the engine performance, because a higher viscosity can cause excessive fuel injection pressures for the engine warm-up, increasing the energy demand of pumps and tending to form larger droplets up, leading to a poorer spray. Those phenomena can cause an incomplete combustion, wear of the fuel pump elements, choking of the fuel injectors, and ring carbonization (Baroutian et al., 2010; Freitas et al., 2011). Therefore, the viscosity must meet the parameters established in the legislation so that it can ensure the efficiency of combustion since density and viscosity of biodiesel are two important physical properties because they are widely used in combustion models, design-operation-control of processes, and fuel quality (Ramírez-Verduzco, 2013).

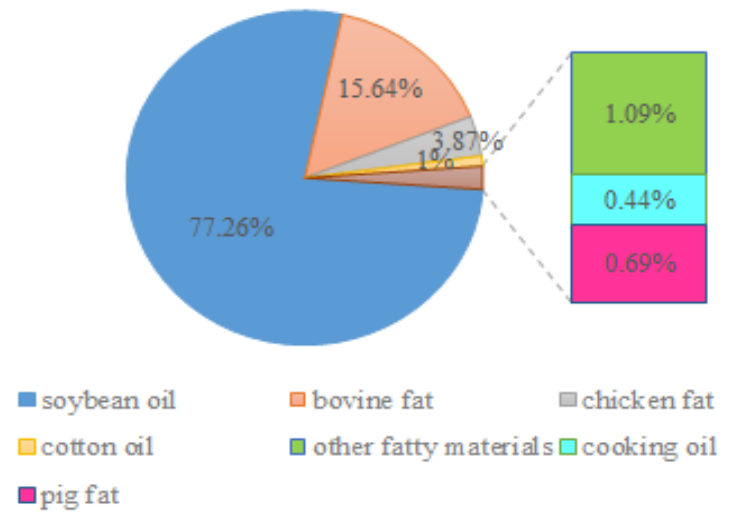

Figure 4. Raw materials used in the production of biodiesel in July 2014. Source: Adapted (www.anp.gov.br. Accessed on September 24, 2014).

\section{CONCLUSIONS}

The following conclusions can be drawn according to the present study:
The viscosity of all oils showed a decrease with the increase in temperature. The oils analyzed behaved as Newtonian fluids. The models of Newton and Ostwald-de-Waelle are appropriate to represent the rheological behavior of vegetables oils.

\section{ACKNOWLEDGEMENTS}

The authors gratefully acknowledge the financial support of the CNPq/FINEP/RECOGÁS.

\section{REFERENCES}

Anand, K., Ranjan, A., and Mehta, P. S., 2009, Estimating the Viscosity of Vegetable Oil and Biodiesel Fuels, Energy Fuel, Vol. 24, No. 1, pp. 664-672.

Ashraful, A. M., Masjuki, H. H., Kalam, M. A., Rizwanul Fattah, I. M., Imtenan, S., Shahir, S. A., and Mobarak, H. M., 2014, Production and Comparison of Fuel Properties, Engine Performance, and Emission Characteristics of Biodiesel from Various Non-Edible Vegetable Oils: A Review, Energy Conversion and Management, Vol. 80, pp. 202-228.

Azam, M. M., Waris A., and Nahar, N. M., 2005, Prospects and Potential of Fatty Acid Methyl Esters of Some Non-Traditional Seed Oils for Use as Biodiesel in India, Biomass and Bioenergy, Vol. 29, No. 4, pp. 293-302.

Bankovic-ili'c, I. B., Stamenkovi'c, O. S., and Veljkovi'c, V. B., 2012, Biodiesel Production from Non-Edible Plant Oils, Renewable and Sustainable Energy Reviews, Vol. 16, No. 6, pp. 3621-3647.

Baroutian, S., Aroua, M. K., Raman, A. A. A., and Sulaiman, N. M. N., 2010, Viscosities and Densities of Binary and Ternary Blends of Palm Oil + Palm Biodiesel + Diesel Fuel at Different Temperatures, Journal of Chemical and Engineering. Vol. 55, No. 1, pp. 504-507.

Brock, J., Nogueira, M. R., Zakrzevski, C., Corazza, F. de C., Corazza, M. L., and Oliveira, J. V., 2008, Determinação Experimental da Viscosidade e Condutividade Térmica de Óleos Vegetais, Food Science and Technology, Vol. 28, No. 3, pp. 564570. (in Portuguese)

Candeia, R. A., Sinfrônio, F., Bicudo, T., Queiroz, N., Barros Filho, A., Soledade, L., Santos, I., and Souza, A., 2011, Influence of the Storage on the Thermo-Oxidative Stability of Methyl and Ethyl Esters by PDSC, Journal of Thermal Analysis and Calorimetry, Vol. 106, No. 2, pp. 581-586.

Carlsson, A. S., 2009, Plant Oils as Feedstock Alternatives to Petroleum - a Short Survey of Potential Oil Crop Platforms, Biochimie, Vol. 91, No. 6, pp. 665-670.

Conceição, M. M., Candeia, R. A., Dantas, H. J., Soledade, L. E. B., Fernandes Jr., V. J., and Souza, A. G., 2005, Rheological Behavior of Castor Oil 
Biodiesel, Energy \& Fuels, Vol. 19, No. 5, pp. 21852188.

Esteban, B., Riba, J., Baquero, G., Rius, A., and Puig, R., 2012, Temperature Dependence of Density and Viscosity of Vegetable Oils, Biomass and Bioenergy, Vol. 42, pp. 164 -171.

Franco, Z., and Nguyen, Q. D., 2011, Flow Properties of Vegetables Oil-Diesel Fuel Blends, Fuel, Vol. 90, No. 2, pp. 838-843.

Freitas, S. V. D., Pratas, M. J., Ceriani, R., Lima, A. S., and Coutinho, J. A. P., 2011, Evaluation of Predictive Models for the Viscosity of Biodiesel, Energy Fuels, Vol. 25, No. 1, pp. 352-358.

Gao, Y., and Li, K., 2012, New Models for Calculating the Viscosity of Mixed Oil, Fuel, Vol. 95, pp. 431-437.

Hossain, A. B. M. S., Boyce, A. N., Salleh, A., and Chandran, S., 2010, Impacts of Alcohol Type Ratio and Stirring Time on the Biodiesel Production from Waste Canola Oil, African Journal of Agricultural Research, Vol. 5, No. 14, pp. 1851-1859.

Kargbo, D. M., 2010, Biodiesel Production from Municipal Sewage Sludges, Energy Fuels, Vol. 24, No. 5, pp. 2791-2794.

Kelessidis, V. C., Mihalakis, A., and Tsamantaki, C., 2005, Rheology and Rheological Parameter Determination of Bentonite-Water and Bentonite-Lignite-Water Mixtures at Low and High Temperatures, in: Proceedings of the 7th World Congress of Chemical Engineering, Glasgow, pp. 1113.

Lin, C., and Hsiao, M. C., 2013, Optimization of Biodiesel Production from Waste Vegetable Oil Assisted by Co-Solvent and Microwave Using a Two Step Process, Journal of Sustainable Bioenergy Systems, Vol. 3, No. 1, pp.1-6.

Lôbo, I. P., Ferreira, S. L. C., and Cruz, R. S., 2009, Biodiesel: Quality Parameters in Analytical Methods, Química Nova, Vol. 32, No. 6, pp. 15961608.

Melo, M. A. M. F., 2010, Avaliação das Propriedades de Óleos Vegetais visando a Produção de Biodiesel, Master Thesis, UFPB, João Pessoa, PB. (in Portuguese)

Pignelli, A. L. M. T., 2010, Estudo da extração Mecânica e da Transesterificação Etílica de Óleos Vegetais, Doctoral Thesis, Universidade Estadual de Campinas, Campinas, SP. (in Portuguese)

Rajasekar, E., and Selvi, S., 2014, Review of Combustion Characteristics of CI Engines Fueled with Biodiesel, Renewable and Sustainable Energy Reviews, Vol. 35, pp. 390-39.

Ramírez-Verduzco, L. F., 2013, Density and Viscosity of Biodiesel as a Function of Temperature: Empirical Models, Renewable and Sustainable Energy Reviews, Vol. 19, pp. 652-665.

Rizwanul Fattah, I. M., Masjuki, H., Liaquat, A., Ramli, R., Kalam, M., and Riazuddin, V., 2013, Impact of Various Biodiesel Fuels Obtained from Edible and Non-Edible Oils on Engine Exhaust Gas and Noise Emissions, Renewable and Sustainable Energy Reviews, Vol. 18, pp. 552-567.

Rodrigues Filho, M. G., Souza, A. G., Santos, I. M. G, Bicudo, T. C., Silva, M. C. D., Sinfrônio, F. S. M., and Vasconselos, A. F. F., 2009, Antioxidative Properties of Hydrogenated Cardanol for Cotton Biodiesel by PDSC and UV/VIS, Journal of Thermal Analysis and Calorimetry, Vol. 97, No. 2, pp. 605609.

Saad, E. B., 2005, Etanólise do Óleo de Milho Empregando Catalisadores Alcalinos e Enzimáticos, Master Thesis, UFPR, Curitiba, PR. (in Portuguese)

Santos, J. C. O., Santos, I. M. G., and Souza, A. G., 2005, Effect of Heating and Cooling on Rehological Parameters of Edible Vegetable Oils, Journal of Food Engineering, Vol. 67, No. 4, pp. 401405.

Schramm, G., 2006, Reologia e Reometria Fundamentos Teóricos e Práticos, São Paulo: Editora Artliber. (in Portuguese)

Selim, M.Y. E., 2009, Reducing the Viscosity of Jojoba Methyl Ester Diesel Fuel and Effects on Diesel Engine Performance and Roughness, Energy Conversion and Management, Vol. 50, No. 7, pp. 1781-1788.

Stavarache, C., Vinatoru, M., Nishimura, R., and Maeda, Y., 2005, Fatty Acids Methyl Esters from Vegetable Oil by Means of Ultrasonic Energy, Ultrasonics Sonochemistry, Vol. 12, No. 5, pp. 367372.

Tan, P. Q., Hu, Z. Y., Lou, D. M., and Li, Z. J., 2012, Exhaust Emissions from a Light-Duty Diesel Engine with Jatropha Biodiesel Fuel, Energy, Vol. 39, No.1, pp. 356-362.

Tabilo-Munizaga, G., and Barbosa-Cánovas, G. V., 2005, Rheology for the Food Industry, Journal of Food Engineering, Vol. 67, No.1-2, pp. 147-156.

Yilmaz, N., and Morton, B., 2011, Effects of Preheating Vegetable Oils on Performance and Emission Characteristics of Two Diesel Engines, Biomass and Bioenergy, Vol. 35, No. 5, pp. 20282033. 